\title{
Function or fashion? Reply to Martin Haspelmath ${ }^{1}$
}

BART GEURTS

This is the final episode, at least as far as this journal is concerned, in an exchange between Martin Haspelmath and myself concerning the nature of grammaticalization. It started when Haspelmath (1999) argued that the standard view of grammaticalization will not do and requires a thorough overhaul, which he went on to provide. In my reply I tried to show that Haspelmath's diagnosis was overly pessimistic, and that the extension he proposed was not necessary (Geurts 2000), whereupon Haspelmath defended his proposal in the same volume by countering various objections I had launched against it (Haspelmath 2000).

It is not the purpose of this note to establish that I was right and Haspelmath was wrong. Since I don't believe the matter is clear-cut, there would be little point in attempting that. Rather, what I want to do is try to clarify what the discussion is about and highlight a number of themes that I consider to be of particular importance. In doing so I will address some but not all of the points raised by Haspelmath in his reply.

As I understand it, the main issue between Martin Haspelmath and myself is the following. According to the view that I defend, grammaticalization processes take place in a field of force created by a pair of opposing constraints, efficiency and effectiveness. On the one hand, speakers like their means of communication to be efficient, but on the other hand communication must be effective, too, in the sense that a speaker always wants to get his meaning across. It is plain that these two requirements pull in opposite directions. Ultimate efficiency would be achieved by a message that cost no energy at all, and would therefore sound like this: " ". Optimum communicative effectiveness, by contrast, would generally call for more elaborate messages than time and patience permit. What I call the standard account sees grammaticalization as resulting from the interplay between these two forces. According to this view, what causes grammaticalization is that speakers want their communicative devices to be effective as well as efficient. 
Haspelmath argues that this will not do. To be sure, he doesn't hold that the standard account is completely on the wrong track, since he takes over its conceptual machinery wholesale, but he maintains that the standard equipment is not sufficient to account for grammaticalization. What is called for, in his view, is additional constraints, which (and this is really the heart of the matter) have nothing to do with communication per se. Haspelmath's maxims of extravagance and conformity incite a speaker to innovative and conservative language behavior, respectively, not in order to grease the wheels of communication, but to enhance or consolidate the speaker's social status. Hence, Haspelmath would have us believe that the causes of grammaticalization are akin to the forces that drive changes in fashion. This is what I take to be his main point; it is also my main worry.

In his reply, Haspelmath makes a distinction between reduction-first and periphrasis-first models of grammaticalization, relegating me and my version of the standard theory to the former category, while embracing the latter view himself. On a reduction-first account, the process of grammaticalization doesn't start until an existing form is reduced to such a degree that it is felt to be insufficient (for whatever reason). A periphrasisfirst account, by contrast, does not assume that reduction is a necessary condition for grammaticalization. Haspelmath (2000) shows quite convincingly that reduction-based models are inadequate: it is simply not the case that grammaticalization processes are always initiated by attrition of an extant form. As far as I can see, however, the distinction between reduction-first and periphrasis-first models is orthogonal to the issue I wanted to raise. I realize that certain remarks in my initial comment can be construed as endorsing a reduction-first model of grammaticalization, but this was not what I had in mind, and I fully agree with Haspelmath's remark that it would be "very odd" to claim that the standard theory of grammaticalization adopts the reduction-first view. Not to mince words: it would be wrong.

The standard account of grammaticalization explains the process in terms of communicative efficiency and effectiveness. Haspelmath's proposal is really a radical departure from this in that he approaches the phenomenon in sociological terms. Discarding all nuances, his suggestion is the following: if a language changes, it is because speakers want to stand out and therefore start to play around with linguistic material (following the maxim of extravagance), and if a language doesn't change it is because speakers choose to act as other speakers do (following the maxim of conformity). According to the standard picture of grammaticalization, form follows function; Haspelmath's position suggests a different slogan: form follows fashion. This is a caricature, to be sure, 
but it brings out the essential point, which is that Haspelmath focuses on factors that have nothing to do with communication.

One of the reasons for me to balk at Haspelmath's notion of extravagance was that I failed to see how anything I would be willing to call by that name could be a major factor in such an orderly phenomenon as grammaticalization. It is widely accepted, I believe, that grammaticalization processes tend to follow certain well-established trajectories. For example, a considerable body of work has demonstrated that a grammatical tense or aspect marker can usually be traced back to one of a highly restricted class of lexical sources, and that the development of the former out of the latter is surprisingly regular (see e.g. Bybee et al. 1994). This is not the kind of systematicity one would expect if grammaticalization were like a spreading fashion. Furthermore, whereas fashions are shortlived almost by definition, grammaticalization tends to be a slow process, and it is hard to see how, in any particular case, the tradeoff between extravagance and conformity can continue to be a relevant factor for a period of thousand years or more.

Haspelmath draws a parallel between grammaticalization and lexical change, suggesting that both processes are driven by speakers' urge to be noticed or acquire prestige by using novel expressions. I agree with Haspelmath that lexical change is much like the coming and going of fashions. New words enter the language on a daily basis, often beginning their career in linguistic avant-garde circles, from where they infect the larger community, sometimes in a matter of months. This, it seems to me, is the kind of process that an extravagance-based model fits very well, because it is very much like the way a new type of trousers or electronic gadget finds a market. But I doubt that grammaticalization is like this, at all, for reasons given above and in my response to Haspelmath's original article. However, it may be possible to bring together lexical change and grammaticalization, after all, by taking the former as a breeding ground for the latter. Viewing language in evolutionary terms, the idea is that lexical change, which is swift and relatively unsystematic, creates the variation that feeds grammaticalization processes, which are slow and more regular. If this picture is correct, Haspelmath's views and mine are fully compatible; it is just that we are focusing on different parts of the processes turning words into grammatical devices

Another matter that I would like to comment upon concerns the use of intentional terminology in a theory of language change. Following Keller (1994), Haspelmath seeks to account for grammaticalization in terms of a set of "maxims of action," which include his maxims of extravagance and conformity besides the more orthodox maxims of 
efficiency and effectiveness. I objected to this terminology on the grounds that only some aspects of grammaticalization (or language change in general) may be traced down to deliberate actions performed by individual speakers. Put otherwise, my objection was that not all features of any given utterance can be attributed to a decision, properly so called, on the part of the speaker. In his reply, Haspelmath counters by stating that the distinction between intentional and nonintentional actions is impossible to draw and therefore beside the point: "in general all aspects of intentional human actions can be regarded as 'subactions' themselves." I don't believe this is correct. It may sometimes be difficult to say if an event counts as an intentional action or not, but that doesn't disqualify the distinction as such. And in most cases the distinction is clear enough. If I use the proper name "Augustus" to refer to first Roman emperor (rather than, say, "Octavian" or "the first Roman emperor"), it is evident that I have performed an intentional act. If, on the other hand, an Englishman pronounces a French sentence with an English accent, it is presumably not his intention to put on an accent. The difference is palpably clear, and it is an important one, too, because the underlying cognitive processes are different, as well, and in a way that matters to a theory of language change, if only because I can decide to say "Octavian" instead of "Augustus," whereas an Englishman cannot decide not to have an English accent anymore.

There is another way of looking at Haspelmath's use of the term "maxim," which is instructive, I believe, because it relates to his views on language change. There may be all sorts of reasons why a speaker speaks as he does: he may want to disseminate information, convince his audience, impress it with his style, ridicule his opponent, and so on. Furthermore, a speaker may be pursuing any number of goals at the same time. However, only some of these goals count as communicative goals, and it has become common in the literature to say that a goal $\mathrm{G}$ is a communicative goal only if the speaker intends his audience to recognize that he is pursuing $G$, and it is essential to his success that this be recognized. This is the notion of communicative goal that underlies Grice's maxims, and in this respect, too, the maxims introduced by Haspelmath and Keller imply a clear break with tradition: if my goal is to impress my audience, then in general I DON'T want them to realize it. This doesn't show that Haspelmath's stance on grammaticalization is wrong, of course. It is merely to say that his account obliterates certain distinctions that we might want to keep.

Although I have presented myself as defending the standard theory of grammaticalization, I have to admit that there is really no such thing. Indeed, it is fair to say, I believe, that there is No fully developed theory 
of grammaticalization, be it standard or not. However, there is a more or less standard way of looking at grammaticalization processes, which I took and refined in certain respects. One of these respects is especially dear to me, and I want to elaborate on it for one or two paragraphs, because it appears to have been overlooked by Haspelmath, and he may not be the only one to have done so. The problem is the following. Suppose we have a grammatical form $\alpha$ that, due to the drive toward efficiency, becomes reduced to the point that it is not sufficiently effective anymore. The question is why the drive toward efficiency couldn't PREVENT $\alpha$ from ever reaching that point. Or, in other words, how is it possible for $\alpha$ to erode beyond the point where it was clearly on its way to becoming ineffective? My suggestion was that this is possible if $\alpha$ 's effectiveness isn't compromised in all its uses. For example, what allows a negative expression to wear down is the fact that in most cases negatives aren't focused. As long as it is effective in sufficiently many contexts, an expression may continue to wear down and thereby cease to be effective in all contexts.

Haspelmath rejects this solution on the grounds that it entails "dysfunctional erosion":

[Geurts's explanation] seems to presuppose that an element will maintain its identity independently of the context in which it occurs - if it gets reduced in context A, it will do so in context B as well by necessity. But of course there is no such necessity. [...] Thus, Latin non eroded to ne in nonfocused negation (ego non vado $>$ je ne vais 'I don't go'), but when non was focused and stressed, French could have preserved it uneroded (ego NON vado>\#je non vais), instead of introducing a periphrastic locution ( je ne vais pas). (In fact, such a split of Latin non did take place: it is the ancestor of both ne and non 'no'.) Thus, Geurts's argument works only if such contextually conditioned splits were impossible, but in fact they are quite ordinary events in language change (Haspelmath 2000: 793).

I agree with almost everything in this passage (except for a proviso with respect to the last claim, which I will come to in a moment). However, it should be noted that "dysfunctional erosion" is not as weird a concept as Haspelmath makes it out to be. For example, in some dialects of English there is no audible difference between can and can't any more, and although my personal experience with spoken English is rather limited, I have witnessed several exchanges where this nondistinction caused confusion.

Still, why doesn't modern French allow for je non vais pas as a more emphatic alternative to je ne vais pas? Why is it that the splits Haspelmath alludes to sometimes occur and sometimes fail to, even if they would appear to be justifiable? The answer I propose (following a suggestion I 
made in my first reply) is that this, too, is due to a tradeoff between efficiency and effectiveness. If linguistic expressions should spawn variants whenever it would serve effectiveness (or clarity or explicitness or whatever you choose to call it), we would soon be saddled with a monstrously large language, and efficiency would be lost completely.

If this is on the right track, then there are at least two ways effectiveness and efficiency affect the linguistic behavior of individual speakers. On the one hand, every single UTTERANCE is a balancing act between these two forces. On the other hand, the same pair of forces constrains the growth of a speaker's LANGUAGE, which must find a balance between diversification and simplicity. A speaker who didn't care for efficiency (perhaps because he had a prodigious memory and only talked to himself) would soon have a vocabulary of gargantuan propportions, whereas a speaker who cared too much would tend not to distinguish between expressions that his neighbors preferred to keep apart.

This idea, that the same forces may affect the process of language change on different levels, seems evidently correct to me (although I can't recall having seen it in print before) and promising enough to be explored further.

Received 28 September 2000

Humboldt University, Berlin University of Nijmegen

Note

1. Correspondence address: Department of Philosophy, University of Nijmegen, Postbox 9103, 6500 HD Nijmegen, The Netherlands. E-mail: bart.geurts@phil.kun.nl.

\section{References}

Bybee, Joan; Perkins, Revere; and Pagliuca, William (1994). The Evolution of Grammar: Tense, Aspect, and Modality in the Languages of the World. Chicago: University of Chicago Press.

Geurts, Bart (2000). Explaining grammaticalization (the standard way). Linguistics 38(4), 781-788.

Haspelmath, Martin (1999). Why is grammaticalization irreversible? Linguistics 37(6), $1043-1068$.

- (2000). The relevance of extravagance: a reply to Bart Geurts. Linguistics 38(4), 789-798.

Keller, Rudi (1994). On Language Change: The Invisible Hand in Language. London: Routledge. 